\title{
Plasma Levels of Aldosterone, Corticosterone, 11-Deoxycorticosterone, Progesterone, 17-Hydroxyprogesterone, Cortisol, and Cortisone During Infancy and Childhood
}

\author{
WOLFGANG G. SIPPELL, HELMUTH G. DÖRR, FRANK BIDLINGMAIER, AND DIETRICH KNORR \\ Division of Pediatric Endocrinology, Department of Pediatrics, Dr. von Haunersches Kinderspital, University of \\ Munich School of Medicine, Munich, West Germany
}

\section{Summary}

Plasma aldosterone (A), corticosterone (B), deoxycorticosterone (DOC), progesterone (P), 17-hydroxyprogesterone (17-OHP), cortisol $(F)$, and cortisone $(E)$ were measured simultaneously by specific radioimmunoassays in small plasma samples obtained from 174 normal infants and children between $2 \mathrm{hr}$ and $15 \mathrm{yr}$ of age. The significantly elevated neonatal mean levels $(\mathrm{ng} / \mathrm{ml})$ of 2.5 (A), 4.1 (DOC), $53.0(\mathrm{P})$, and 6.6 (17-OHP) dropped significantly during infancy reaching prepubertal levels between 3 months and $3 \mathrm{yr}$ of age, with a transient, significant DOC increase between 1$7 \mathrm{yr}$. The glucocorticoids $\mathrm{F}$ and $\mathrm{B}$ declined significantly from means of 68 and 4.4 to 11.4 and $0.28 \mathrm{ng} / \mathrm{ml}$, respectively, during the first weeks of life, then increased significantly reaching adult levels between 1-3 yr of age. Mean $\mathrm{E}$ fell progressively from 74 $\mathrm{ng} / \mathrm{ml}$ after birth to $10 \mathrm{ng} / \mathrm{ml}$ during $1-5 \mathrm{yr}(P \ll 0.0001)$, then slightly increased to adult levels. After age $7 \mathrm{yr}, \mathrm{P}$ and 17-OHP, in contrast to the other steroids, rose significantly in both boys and girls relative to pubertal development.

The observed changes are thought to be due to (1) adaptation of the adrenal neocortex to extrauterine life after disruption of the fetoplacental unit, (2) a physiologic lack of corticosteroid binding globulin (CBG) during infancy due to maturation of hepatic CBG biosynthesis, (3) the functional immaturity of the infant kidney compensated by an increased activity of the renin-angiotensin-aldosterone system, and (4) gradually increasing gonadal secretion of progestins during puberty.

\section{Speculation}

From birth to adulthood, marked evolutional changes were observed in the basal plasma concentrations of all physiologically important unconjugated corticosteroids and progestins in normal children. Detailed knowledge of the age-dependent normal plasma steroid pattern reflecting maturational processes of both the hypothalamo-adrenocortical and the hypothalamo-gonadal axis, of the renin-angiotensin-aldosterone system, and of hepatic and renal function, therefore, is a prerequisite for understanding pathologic conditions in pediatric endocrinology.

Among the major physiologic plasma corticosteroids and their precursors, only the mineralocorticoid aldosterone has been studied systematically in children from birth to adulthood in several reports $(13,30,39,42,52)$ showing significantly higher levels in infants than in older children and adults. In one of these studies (52), levels of the main glucocorticoid, cortisol, were reported for comparison. These levels, however, did not differ from those found in healthy adults. There is no indication to date whether other mineralocorticoids like DOC, and glucocorticoids like B and E exhibit similar patterns in different pediatric age groups or not. Recently published data on the progestins $\mathrm{P}$ and 17-OHP with one exception (23) only covered either infancy (17) or puberty (4, $33,34)$. Yet, a detailed evaluation of adrenocortical function is frequently needed in infants and children presenting with such various symptoms as salt loss, virilization, staunted or excessive growth, obesity, premature pubarche, hypertension, etc., for which appropriate, age-matched control values of adrenal steroids are of fundamental importance.

The scantiness, and often complete lack of information available on control data of plasma steroids in children is primarily due to the large quantities of blood previously required for their determination and the sampling difficulties encountered in young children. It prompted us to study these important parameters of adrenocortical function in a large number of normal children throughout all pediatric age groups using our recently developed method for the simultaneous determination of eight plasma steroids by radioimmunoassay (46) requiring only $1-3 \mathrm{ml}$ of peripheral blood.

\section{MATERIALS AND METHODS}

A total of 174 infants and children ( 83 boys and 91 girls), aged $2 \mathrm{hr}-15 \mathrm{yr}$, were studied. The newborn infants were all products of uncomplicated, full term pregnancies and were born by vaginal delivery after labor of spontaneous onset. Infants and children over 2 wk of age were either admitted for minor disorders or for observation, or were seen at the Outpatient Department and required venepuncture for diagnostic reasons. In addition, informed consent was obtained from the mothers, fathers, or guardians. In the two oldest age groups (7-15 yr), there were 26 boys and 26 girls whose pubertal development (53) ranged from Stage $1-4$, and from Stage 1-5, respectively. Only 5 of these girls were after menarche. All subjects included in the present study were without evidence of endocrine, renal, circulatory, or any other systemic disease and did not show disturbances of acid base or electrolyte metabolism. They were on random diets and were in normal, unrestrained activity just before blood sampling which was performed in supine position by rapid puncture of a scalp or antecubital vein in order to avoid prolonged crying (2).

All blood samples were collected between 8-10 AM in polystyrene tubes containing dried ammonium heparinate and were immediately centrifuged at $4^{\circ} \mathrm{C}$. The $0.5-1.5 \mathrm{ml}$ of plasma to be used for determination of the 7 steroids were stored at $-20^{\circ} \mathrm{C}$ until assay.

The simultaneous multiple steroid radioimmunoassay procedure including a mechanized Sephadex LH-20 multi-column chro- 
matography developed in this laboratory (47) has been described and evaluated in detail elsewhere (46). Intraassay and interassay coefficients of variation of the complete determination were between $6.9-14.5 \%$, and between $11.9-16.3 \%$, respectively, for the seven steroids studied. Due to the limited amounts of plasma available in some infants and children, several values of DOC and a few of $\mathrm{P}$ and 17-OHP fell below the limit of sensitivity for these steroids $(15-20 \mathrm{pg} / \mathrm{ml})$, causing high sample variations. These values, therefore, had to be assigned a value of $10 \mathrm{pg} / \mathrm{ml}$ in the statistical calculations.

Because the plasma concentrations of each of the 7 steroids showed a normal distribution in every age group after logarithmic transformation, mean values and variations of the sample had to be expressed as geometric means and $90 \%$ confidence intervals (corresponding roughly to a $3.5 \mathrm{SD}$ range), respectively. Statistical comparisons of a given steroid's levels between any of the nine different age groups were performed using the nonparametric ranked analysis of variance according to Kruskal and Wallis (32). Differences between the means of two samples (e.g., boys and girls) were checked by either $t$ test or Mann-Whitney's $U$ test (37).

\section{RESULTS}

Plasma levels (geometric means, and ranges) of the seven steroids determined in 174 normal children which were divided into nine different age groups are compiled in Table 1. In all steroids except cortisol, by far the highest mean levels were found in the neonates, at $2 \mathrm{hr}$ after birth. During infancy and early childhood, steroid levels of the mineralocorticoids A and DOC, of the progestins $\mathrm{P}$ and 17-OHP, and also of $\mathrm{E}$ in general showed a tendency to decrease, whereas the glucocorticoids $\mathrm{F}$ and $\mathrm{B}$, after relatively low levels during infancy, increased. There were no significant sex differences in any age group for all of the seven steroids studied.

\section{ALDOSTERONE}

Individual plasma A levels are plotted in Figure 1 on a logarithmic scale. During the first $\mathrm{yr}$ of life, there was a steep, progressive decline in mean A levels by a factor of 8.6 which, by ranked analysis of variance, was found to be highly significant $(P$ $<10^{-5}$, Table 2). After $1 \mathrm{yr}$ of age, relatively constant mean plasma concentrations were observed, with decreasing variation of individual values. The mean A level in 11- to 15-yr-old children, however, was still somewhat higher than those previously found in a group of ambulatory adult men and women (46).

\section{CORTICOSTERONE}

Plasma B mean levels dropped by almost 16-fold from 4.44 $\mathrm{ng} / \mathrm{ml}$ at $2 \mathrm{hr}$ after birth to $0.28 \mathrm{ng} / \mathrm{ml}$ in early infancy (Table 1). Thereafter, a slight increasing tendency was noted which became significant $(P<0.05)$ at $7-11$ yr of age (Table 2). By linear regression analysis, a positive and significant $(r=+0.238, P<$ $0.01)$ relationship was obtained for the age range between 7 days$15 \mathrm{yr}$.

\section{DEOXYCORTICOSTERONE}

Similar to aldosterone, DOC, the second mineralocorticoid studied, showed an overall decrease of its plasma levels from birth-15 yr of age (Table 1). During the first wk of life, DOC mean levels fell steeply by more than two orders of magnitude; this drop, of course, was highly significant $\left(P<10^{-7}\right.$, Table 2$)$. Moreover, Table 2 indicates that mean DOC levels, though varying widely, increased significantly after the first yr of life, reaching a significant plateau between $1-7 \mathrm{yr}$ of age and subsequently declined again.

Table 1. Plasma concentrations $(\mathrm{ng} / \mathrm{ml})$ of seven corticosteroids and progestins in 174 normal children $(8-10$ AM, unrestrained activity, random diets) from $2 \mathrm{hr}-15 \mathrm{yr}$ of age

\begin{tabular}{|c|c|c|c|c|c|c|c|c|c|}
\hline Steroid & $2 \mathrm{hr}$ & 7 days & $\begin{array}{l}2 \text { wk- } \\
3 \text { months }\end{array}$ & $\begin{array}{c}3 \text { months- } \\
1 \mathrm{yr}\end{array}$ & $1-3 \mathrm{yr}$ & $3-5$ yr & $5-7$ yr & $7-11 \mathrm{yr}$ & $11-15 \mathrm{yr}$ \\
\hline \multirow{3}{*}{ A } & $2.51^{1}$ & 0.87 & 0.64 & 0.29 & 0.30 & 0.28 & 0.30 & 0.34 & 0.36 \\
\hline & $1.20-8.51^{2}$ & $0.35-2.11$ & $0.14-1.05$ & $0.06-0.92$ & $0.10-0.79$ & $0.11-0.67$ & $0.18-0.69$ & $0.10-0.62$ & $0.14-0.88$ \\
\hline & $12^{3}$ & 20 & 11 & 23 & 20 & 17 & 19 & 27 & 25 \\
\hline \multirow{3}{*}{ B } & 4.44 & 0.50 & 0.28 & 0.48 & 1.07 & 1.27 & 0.80 & 1.39 & 0.74 \\
\hline & $0.48-46.0$ & $<0.05-11.3$ & $<0.05-3.46$ & $<0.05-5.51$ & $<0.05-8.48$ & $0.29-9.37$ & $<0.05-6.45$ & $<0.05-12.2$ & $<0.05-4.93$ \\
\hline & 12 & 20 & 11 & 23 & 20 & 17 & 19 & 27 & 24 \\
\hline \multirow{3}{*}{ DOC } & 4.06 & 0.045 & 0.019 & 0.017 & 0.084 & 0.075 & 0.059 & 0.020 & 0.029 \\
\hline & $1.52-18.7$ & $<0.03-0.45$ & $<0.03-0.37$ & $<0.03-0.33$ & $<0.03-0.33$ & $<0.03-0.28$ & $<0.03-0.37$ & $<0.03-0.23$ & $<0.03-0.19$ \\
\hline & 12 & 20 & 11 & 23 & 14 & 16 & 19 & 27 & 25 \\
\hline \multirow{3}{*}{$\mathbf{P}$} & 53.0 & 0.20 & 0.34 & 0.24 & 0.34 & 0.20 & 0.36 & 0.10 & 0.37 \\
\hline & $27.8-103$ & $<0.03-2.13$ & $<0.03-0.99$ & $<0.03-1.26$ & $0.06-0.74$ & $<0.03-0.95$ & $0.08-0.89$ & $<0.03-0.96$ & $<0.03-0.99$ \\
\hline & 12 & 20 & 11 & 23 & 16 & 16 & 19 & 23 & 24 \\
\hline \multirow{3}{*}{ 17-OHP } & 6.62 & 0.91 & 0.79 & 0.33 & 0.20 & 0.28 & 0.14 & 0.33 & 0.45 \\
\hline & $1.55-23.1$ & $0.13-2.46$ & $0.19-2.80$ & $<0.03-1.55$ & $<0.03-0.95$ & $0.05-0.87$ & $<0.03-0.84$ & $<0.03-0.83$ & $0.08-1.63$ \\
\hline & 12 & 20 & 11 & 23 & 17 & 17 & 15 & 23 & 25 \\
\hline \multirow{3}{*}{$\mathrm{F}$} & 68.0 & 11.4 & 33.4 & 63.4 & 75.2 & 73.7 & 78.3 & 79.8 & 64.1 \\
\hline & $12.5-298.0$ & $1.29-96.4$ & $9.24-86.8$ & $21.2-173.0$ & $17.1-137.0$ & $32.4-129.0$ & $39.8-136.0$ & $35.4-184.0$ & $21.7-174$ \\
\hline & 12 & 20 & 11 & 23 & 20 & 17 & 19 & 27 & 25 \\
\hline \multirow{3}{*}{ E } & 73.7 & 18.5 & 22.9 & 16.6 & 10.8 & 9.87 & 14.0 & 15.6 & 14.3 \\
\hline & $26.4-156.0$ & $3.27-45.3$ & $9.10-54.2$ & $7.00-46.0$ & $2.73-26.8$ & $4.72-25.2$ & $7.00-27.0$ & $7.31-37.6$ & $2.31-44.8$ \\
\hline & 12 & 20 & 11 & 23 & 20 & 17 & 19 & 27 & 25 \\
\hline
\end{tabular}

\footnotetext{
${ }^{1}$ Geometric mean.

${ }^{2}$ Range

${ }^{3}$ Number of individual samples.
} 


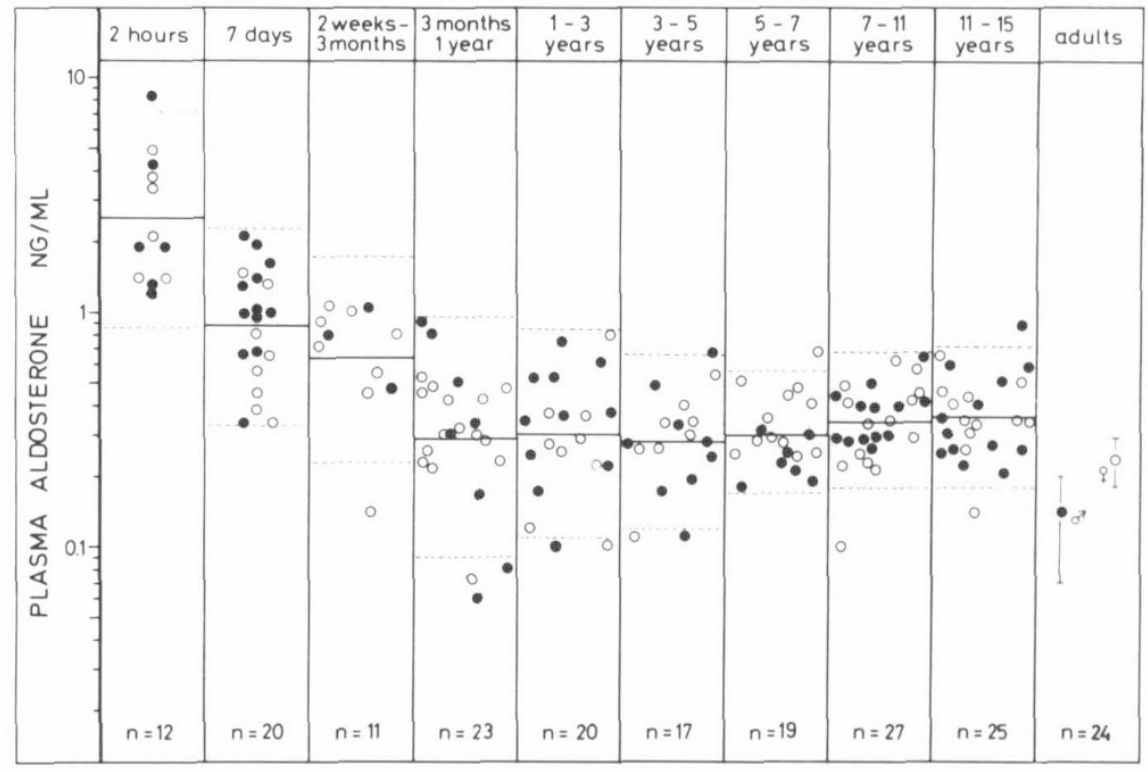

Fig. 1. Semilogarithmic plot of individual AM plasma aldosterone levels (ng/ml) in 174 normal, unrestrained children between $2 \mathrm{hr}$ and $15 \mathrm{yr}$ of age ( 82 boys and 92 girls, all on random diet). Solid and broken horizontal lines represent geometric means and $90 \%$ confidence limits, respectively, in each age group. AM levels in adult, ambulatory men and women on random diet are given for comparison (46).

Table 2. Results of statistical comparisons (ranked analysis of variance) between the nine different age groups (only significant differences are included) ${ }^{1}$

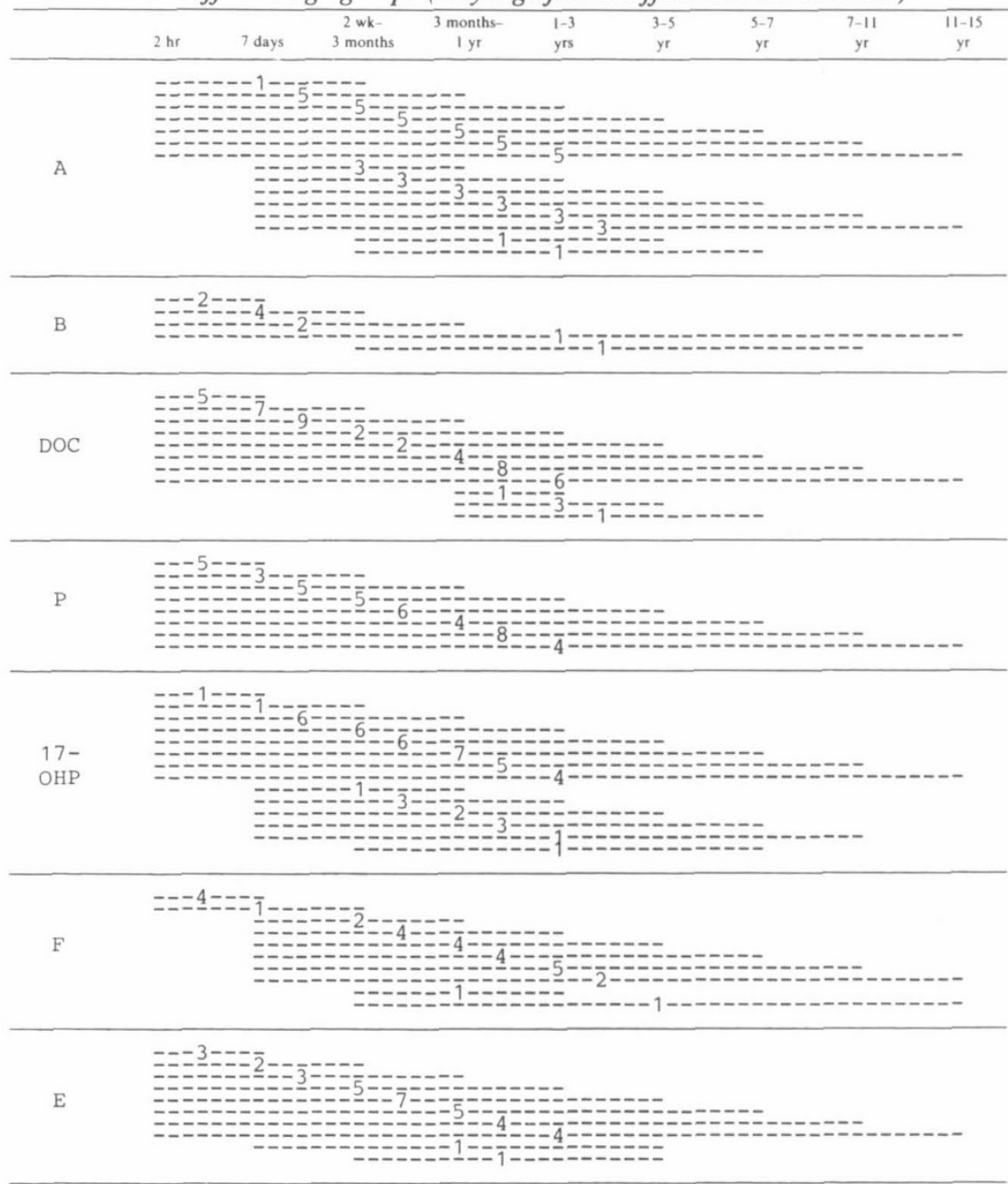

${ }^{1}$ Levels of significance: $1=P<0.05,2=P<0.01,3=P<0.001,4=P<0.0001,5=P$ $<0.00001$, and so forth 


\section{PROGESTERONE}

The extremely high $\mathrm{P}$ levels found $2 \mathrm{hr}$ after birth rapidly faded away during the first wk of life (Table 1). Thereafter, basal $\mathrm{P}$ levels, on the average 150-250 times lower than the initial ones, were found throughout infancy and childhood without significant fluctuations (Table 2).

Over the entire age range, a significant negative correlation was obtained between $\mathrm{P}$ levels and age $(r=-0.532, P \ll 0.001)$.

When male and female P levels were analyzed separately, there was a significant plasma $\mathrm{P}$ increase $(P<0.05)$ between the oldest age groups (7-11 vs. 11-15 yr) in the boys, but not in the girls. Grouping of these data according to pubertal stages revealed a significant rise of $P$ between Stage 1 and 2 in both boys and girls (Table 3). After Stage 2, no further increase of P occurred in these children.

\section{$17 \alpha$-HYDROXYPROGESTERONE}

Mean 17-OHP plasma levels, in contrast to $\mathrm{P}$, exhibited a more gradual decline extending over the first $3 \mathrm{yr}$ of life (Table 1). During the first wk of life, its mean level fell significantly (Table 2) by more than 7 -fold, then showed a plateau around $0.8 \mathrm{ng} / \mathrm{ml}$ until an age of 3 months. This was followed by a second, significant drop to only $5-3 \%$ of its initial neonatal level occuring in the age groups between 3 months- 3 yr. These low 17-OHP levels persisted until age $7 \mathrm{yr}$ when the beginning of a slow pubertal rise could be noted which, however, was significant between the age groups of $5-7$ and $11-15$ yr only when boys $(P<0.05)$ and girls $(P<0.01)$ were considered separately.

When 17-OHP levels in the children over $7 \mathrm{yr}$ of age were arranged according to pubertal stages, a gradual, and in almost every step significant, increase was seen in both sexes (Table 3 ). In the same pubertal stage, mean 17-OHP levels were well comparable between boys and girls.

\section{CORTISOL}

In addition to the mean $\mathrm{F}$ levels listed in Table 1, individual concentrations are logarithmically plotted in Figure 2. Table 2 indicates that the mean $F$ levels measured both at 7 days and between 2 wk-3 months of age were significantly lower than not only the $2 \mathrm{hr}$ levels but also those observed in older infants and children. From the low levels found at 1 wk of age, plasma $\mathrm{F}$ levels rose steadily reaching adult levels at the end of the first year of life (Fig. 2).

Individual variation of $\mathrm{F}$ levels was wide in the neonates and young infants, but gradually narrowed with increasing age (Fig. 2). After $1 \mathrm{yr}$ of age, relatively constant mean levels around 75 $\mathrm{ng} / \mathrm{ml}$ were observed. These were only slightly lower than and not statistically different from those found in adults under similar blood sampling conditions (Fig. 2). As was the case in B, the other important glucocorticoid studied, a highly positive and significant

Table 3. P and 17-OHP levels according to pubertal development ${ }^{1}$

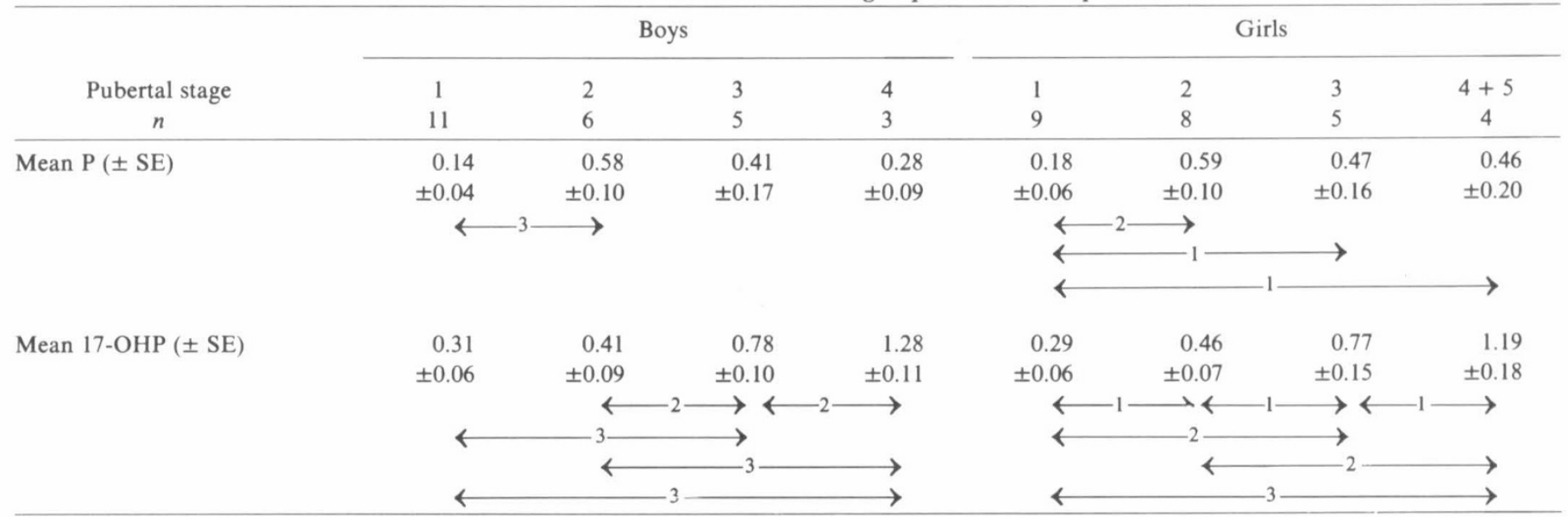

${ }^{1}$ Levels of significance: $1 P<0.05 ; 2 P<0.01 ; 3 P<0.001$.

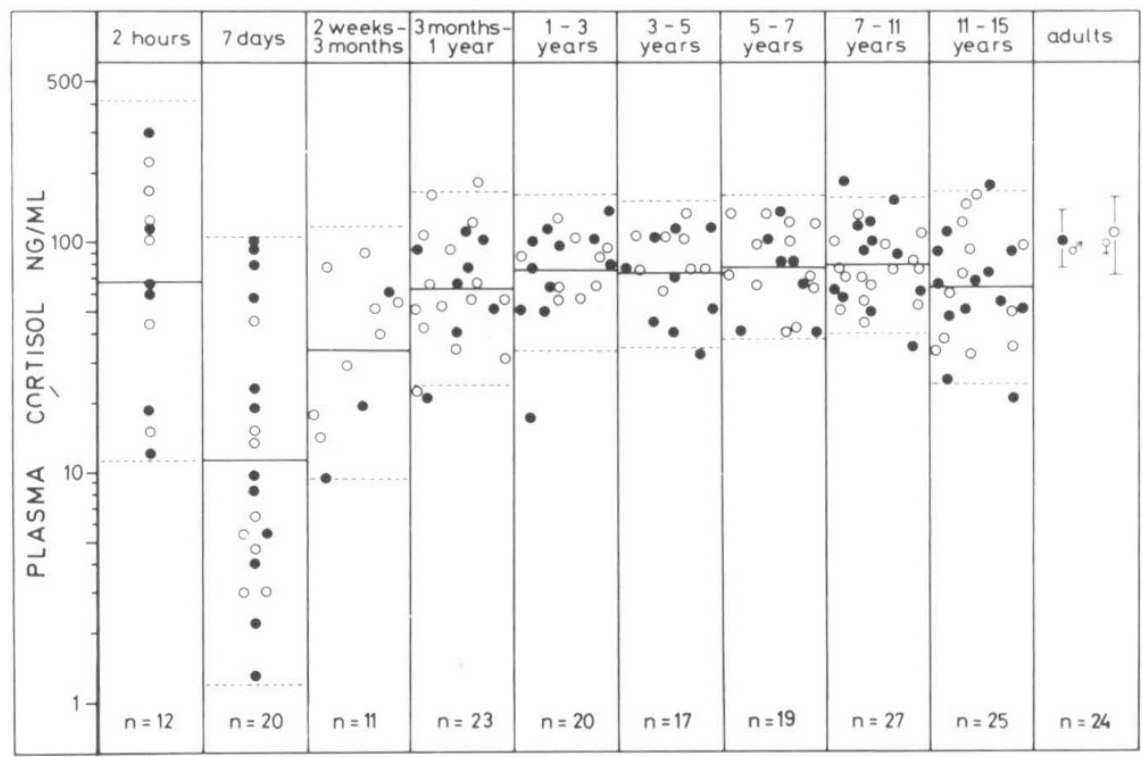

Fig. 2. Individual AM plasma cortisol levels ( $\mathrm{ng} / \mathrm{ml}$, semilogarithmic plot) found in the same normal, unstressed individuals as in Figure 1 . 
relationship between $\mathrm{F}$ levels and age could be observed between 7 days -15 yr $(r=+0.627, P \ll 0.001)$.

\section{CORTISONE}

Individual plasma E levels (Fig. 3) showed a pattern markedly different from that of their equilibrium steroid, cortisol (Fig. 2). Rather than to increase during early infancy and childhood, plasma E levels gradually declined from a mean of $73.7 \mathrm{ng} / \mathrm{ml}$ at $2 \mathrm{hr}$ after birth by a factor of 7.5 to only $10 \mathrm{ng} / \mathrm{ml}$ between $3-5 \mathrm{yr}$ of age (Table 1). This decline was highly significant not only in total $\left(P<10^{-7}\right)$ but also when its single steps were compared with the initial $2 \mathrm{hr}$ levels (Table 2). After $5 \mathrm{yr}$ of age, mean plasma $\mathrm{E}$ concentrations remained rather constant around $15 \mathrm{ng} / \mathrm{ml}$ which was well in the range of the adult levels (Fig. 3).

\section{DISCUSSION}

The present study shows that in normal children the basal plasma levels of individual corticosteroids and progestins differ considerably not only between different pediatric age groups, but also in comparison with adults. In all steroids studied, by far the highest plasma concentrations were observed in the neonates at 2 hr after birth. After the first wk of life, when mean levels had dropped by factors varying between 3 and 265 in A and P, respectively, out of the 7 steroids studied, only $P$ levels were comparable to those observed in later infancy and childhood.

Even basal cortisol plasma levels, to date considered to change very little with age (52) and to be no different in children than in adults $(24,40)$, were significantly lower in our normal infants between 7 days -3 months of age than both below and above this age range. This example already demonstrates the need for properly age-matched control data of plasma steroids in children.

The finding of a much wider variation of basal steroid levels in children than in adults which in all of the 7 steroids studied has been observed particularly during early infancy and childhood is in keeping with the few observations made by other authors on aldosterone $(39,42,52)$ or cortisol (6). It might be due not only to decreased methodologic sensitivity caused by low levels and small amounts of plasma available, but rather to individual differences in hepatic $(7,19,28)$, and in the case of mineralocorticoids, also renal $(15,26)$ maturation during infancy. In addition to the rather scattered basal levels, therefore, plasma steroid levels after adrenal stimulation and/or suppression are needed whenever indicated in order to differentiate clearly between normal and pathologic conditions (6). These tests, however, were ethically not justifiable in the present sample of clinically normal children.

\section{MINERALOCORTICOIDS}

The A values in this study are in full accord with those reported by Stark et al. (52), Dillon and Ryness (13), and Parth et al. (39), when allowance is made for the fact that these authors studied children who were recumbent for at least $2 \mathrm{hr}$, resulting in lower A levels after infancy. Still lower A levels were reported by RauxEurin et al. (42) who also studied supine children. Beitins et al. (8) and Siegler et al. (45), studying infants only, and Kowarski et al. (30), who, although not clearly stated, probably studied ambulatory children, obtained very similar results as the authors did. The latter authors, however, reported significantly lower plasma A levels in newborns below 3 days of age and at birth (cord vein) than in infants between $1 \mathrm{wk}$ and $1 \mathrm{yr}$ of age, a finding that is at variance with both the present data and all other reports covering that age range $(14,42,45,48)$.

Thus, there is now ample evidence that is further supported by similar findings on plasma renin activity $(13,22,43,45,51,52)$ or concentration (31), angiotensin II (41), and by some of the earlier studies on A secretion and excretion rates in children $(38,50,56)$ that the activity of the renin-angiotensin-aldosterone system varies inversely with age from birth to adulthood. This physiologic, agedependent decrease extends into old age (55) and seems to be inversely related to blood pressure. In the present study, too, a highly significant negative correlation was observed between plasma aldosterone levels and age $(r=-0.679, P \ll 0.001)$.

The reasons for this strong age dependency are by no means established at present. Because the steepest decline in both aldosterone and renin plasma levels occurs during early infancy, the functional immaturity of the infant kidney, as indicated by diminished tubular function with a relative insensitivity to aldosterone (15) may be primarily responsible. Besides a slow increase in sodium intake during infancy and the well known loss of extracellular fluid after birth, other possibly contributing factors include an increased activity of the sympathico-adrenergic system (18), the low systemic blood pressure, and the extremely low levels of antidiuretic hormone (26) in infancy, all of which are known to stimulate renin release and subsequently aldosterone secretion.

In addition to the renin-angiotensin system, aldosterone production can be increased by hyperkalemia, sodium depletion, and ACTH. Recently, Siegler et al. (45) were able to demonstrate a significant positive correlation between serum potassium and $\mathrm{A}$ levels in normal infants between 3-12 months of age, whereas Weldon et al. (56) have shown that in infants and young children the increase in A secretion after low sodium intake is similar to that observed in adults. There is no evidence, however, for consistently elevated serum potassium levels and a chronically low

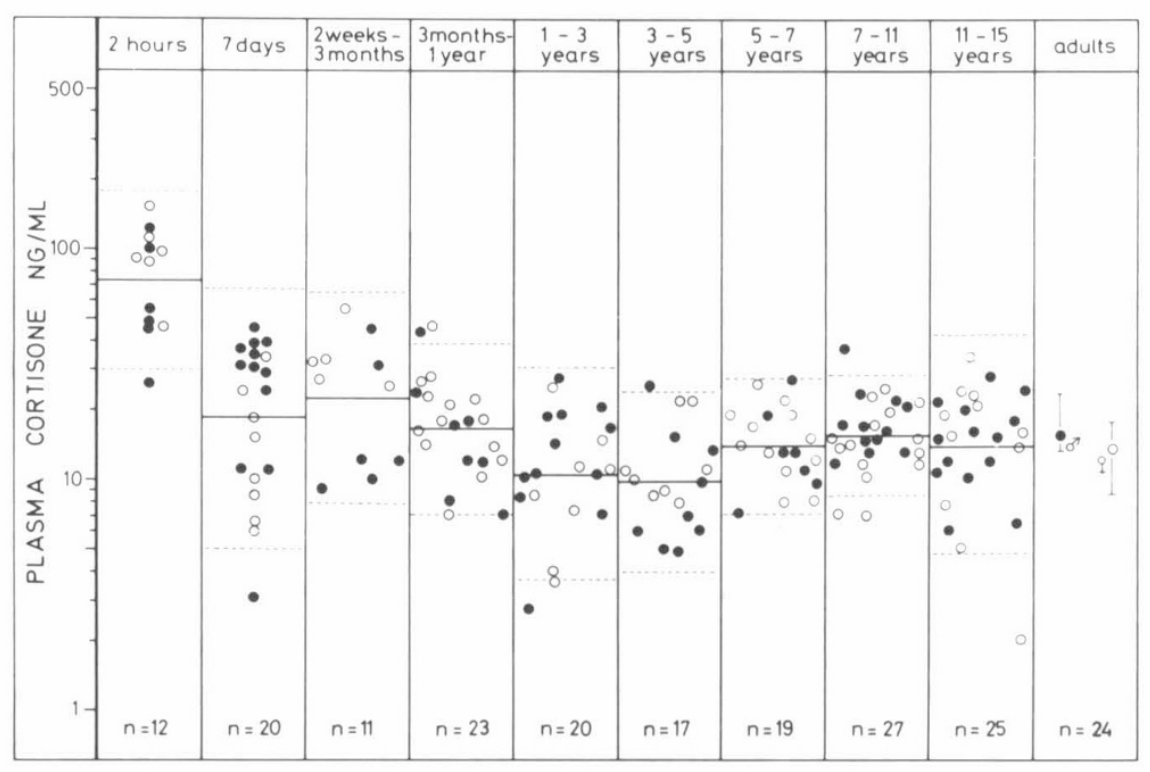

Fig. 3. Individual AM plasma cortisone levels (ng/ml, semilogarithmic plot) found in the 174 normal children. Details as in Figure 1. 
sodium intake in normally fed young infants that would account for the increased renin and aldosterone levels. Finally, stimulation by ACTH could at best be responsible for the highly elevated A levels found at $2 \mathrm{hr}$ after birth, because it has been shown that they coincide with maximum ACTH levels (12) and also with elevated glucocorticoid (F and B) concentrations (Table 1). Later on, however, a considerable ACTH effect seems unlikely, because, in contrast to the negative age dependency of $\mathrm{A}$ levels, both $\mathrm{F}$ and B showed a significantly positive correlation with age.

The present study, to our knowledge, is the first to report plasma DOC levels in infants and children. This mineralocorticoid and its sulfate are a major secretory product of the human fetoplacental unit at term $(11,49)$ which explains the enormously elevated neonatal $2 \mathrm{hr}$ levels. The DOC pattern during infancy and childhood roughly parallels that of aldosterone, its biosynthetic end product. Although DOC levels were widely scattered in normal children, a significant plateau of DOC mean levels was observed from 1-7 yr of age (Table 2). Its physiologic significance is not clear at present. It is interesting, however, that both $\mathrm{B}$ and $\mathrm{F}$ mean levels were somewhat elevated in these age groups, too, and that the $\mathrm{F} / \mathrm{E}$ ratio showed its highest mean level of 7.5 during 3-5 $\mathrm{yr}$ of age. This finding would suggest an increased ACTH stimulation during this age period, because plasma DOC in children shows an even greater response to stress or ACTH administration than both F or B (Sippell, unpublished observation). DOC levels of our children between 7-15 yr of age were in the range found in normal adults (46).

\section{PROGESTINS}

Plasma $P$ reference levels to date have been reported in only very small numbers of infants $(35,54)$ and prepubertal children not subdivided into different age groups $(1,3,25,35,54)$. The $\mathrm{P}$ levels throughout infancy and childhood agree favorably with these data. In all of these reports as well as in the present data, no consistent differences were found in P levels between boys and girls. This finding might indicate, although not prove, that circulating $\mathrm{P}$ in prepubertal children is predominantly of adrenal origin (1).

During puberty, plasma levels of $\mathrm{P}$ and other sex-related steroids recently have extensively been studied in both boys (33) and girls $(4,34,57)$. Whereas in boys, Lee and Migeon (33) observed the major pubertal $P$ rise between Stages 3 and 4, the present study showed a highly significant rise already between Stage 1 and 2 (Table 3). Accordingly, these authors found significantly elevated P levels only after age 15, whereas in the boys in this study, this significant $\mathrm{P}$ rise occurred between the age groups of 7-11 and 11-15 yr. In girls, Apter and Vihko (4) observed, very similar to our findings, significantly rising $P$ levels from Stage $1-3$ and also from Stage $2-5$, whereas other authors $(34,57)$ did not find this pubertal P rise before Stage 4-5.

Levels of 17-OHP have been studied most often simultaneously with $\mathrm{P}(1,3,4,25,33-35,54)$, but also individually $(17,20,23,27$, $36)$ or in combination with other steroids $(5,40,58)$. The majority of these data that in only one report (23) were covering the entire pediatric age period, is in close agreement with those reported here with one exception (40) where, obviously due to a less specific method, considerably higher levels were found. Significantly higher 17-OHP levels in boys than in girls around the second month of life were observed in a large series of normal infants by Winter and coworkers $(23,58)$ and more recently by Forest and Cathiard (17). Moreover, the latter authors found significantly higher 17-OHP levels in 7- to 9-months-old girls than in boys of the same age. These 17-OHP peaks that coincide with similar peaks of gonadotropins, and of testosterone (16) and estradiol (10) in boys and girls, respectively, obviously reflect a transient increase in gonadal activity during infancy. In the present study, the authors did not find significant differences in 17-OHP plasma levels between boys and girls of $2 \mathrm{wk}-1 \mathrm{yr}$ of age. The most obvious reason for this negative result is that in this age range only 12 boys and 22 girls were studied, as compared with the 109 male and 74 female infants studied by Forest and Cathiard (17). In contrast to Hughes and Winter (23), and in accordance with others (4), a transient $17-\mathrm{OHP}$ rise at $8 \mathrm{yr}$ of age was not found.

During puberty, 17-OHP levels were found to increase in both sexes gradually and significantly in relation to pubertal development (Table 3). These findings are in good general agreement with other recent studies $(4,33,34)$ in which $17-\mathrm{OHP}$ also exhibited a more gradual rise than $\mathrm{P}$. That the pubertal increase in plasma $\mathrm{P}$ and 17-OHP is almost exclusively of gonadal rather than adrenal origin is not only evident from the concurrent increases of their gonadal end products, testosterone (29) and estradiol (9), but can also be inferred from the present findings that their adrenal end products, the corticosteroids F, E, B, A, and DOC did not increase during puberty.

\section{GLUCOCORTICOIDS}

To our knowledge, there is no data available on plasma $\mathrm{F}$, E, or B levels measured specifically throughout infancy and childhood. During the early neonatal period, $\mathrm{F}$ and $\mathrm{E}$ have simultaneously been studied by Hillman and Giroud (21) who noted that E levels remain elevated in comparison to $F$ during the first wk of life. This is consistent with the present findings of mean $F / E$ ratios of 0.9 and 0.6 at $2 \mathrm{hr}$ and $1 \mathrm{wk}$ of life, respectively, as compared with $\mathrm{F} / \mathrm{E}$ ratios greater than one invariably observed in the older infants and children. Indeed, the characteristic predominance of $\mathrm{E}$ over $\mathrm{F}$ in cord blood which is due to the extensive $\mathrm{F}$ dehydrogenation by placenta and fetal tissues, has been observed by Seely (44) as early as in 1961. Whereas mean E levels gradually declined during early childhood, the plasma concentrations of $\mathrm{F}$, the major physiologic glucocorticoid in man, exhibited a significant dip at 1 wk of age followed by a progressive rise towards adult levels during the first yr of life (Fig. 2).

More than $10 \mathrm{yr}$ ago, Kenny et al. (28) observed in normal infants between days 5-20 a lower absolute $\mathrm{F}$ production rate than both before or after this age period, whereupon the values steadily rose by a total factor of about 7 until $20 \mathrm{yr}$ of age. It is difficult, however, to reconcile this pattern of $F$ production with that of the F plasma concentrations depicted in Fig. 2, because such an attempt would result in a metabolic clearance rate of $F$ in early infancy about 4 times greater than that found immediately after birth or during later childhood. A more satisfactory explanation for the significantly decreased $F$ levels in early infancy, however, has been provided by the binding studies of Hadjian et al. (19) who demonstrated a markedly decreased transcortin binding capacity and affinity constant in human infants during the first month of life with a gradual rise of both parameters during the following months until normal adult levels were reached after $1 \mathrm{yr}$ of age.

Thus, the characteristics of the $\mathrm{F}$ binding globulin almost exactly parallel the plasma $\mathrm{F}$ levels and also the changes in $\mathrm{F} / \mathrm{E}$ ratios described here, reflecting maturation of hepatic transcortin biosynthesis during the first yr of life. Very similar age dependent changes in plasma $\mathrm{F}$ binding have been found in rhesus monkey infants (7). In this species, however, adult values were reached about 1 yr later. In keeping with our findings, no differences with adult levels have been observed in children over 1 yr of age, even when methods not entirely specific for $F$ were used $(6,24,40,52)$.

Aside from its highly elevated neonatal levels, plasma B showed an age dependency pattern rather similar to, though less conspicuous than that of F. The significant B dip noted in early infancy is again obviously due to the reduced corticosteroid binding globulin concentrations during the first months of life. It is of interest to note that the plasma levels of all other steroids studied, with the possible exception of $\mathrm{E}$ at 7 days of age, are obviously not affected by this physiologic transcortin deficiency, i.e., that similar to what is known in adults, in infants only $\mathrm{F}$ and $\mathrm{B}$ are bound to transcortin to a significant extent.

Although the cross-sectional data provided in the present study are by no means valid in defining the age-related endocrine changes taking place in a particular child, they nevertheless can 
properly be utilized to describe the major trends in mineralo- and glucocorticoid levels occurring in the pediatric population between birth and puberty.

\section{REFERENCES AND NOTES}

1. Abraham, G. E., Hopper, K., Tulchinsky, D., Swerdloff, R. S., and Odell, W. D.: Simultaneous measurement of plasma progesterone, 17-hydroxyprogesterone and estradiol-17 $\beta$ by radioimmunoassay. Anal. Lett., 4: 325 (1971).

2. Anders, T. E., Sachar, E. J., Kream, J., Roffwarg, H. P., and Hellmann, L.; Behavioral state and plasma cortisol response in the human newborn. Pediatrics, 46: 532 (1970).

3. Anderson, D. C., Hopper, B. R., Lasley, B. L., and Yen, S. S. C.: A simple method for the assay of eight steroids in small volumes of plasma. Steroids, 28: 179 (1976).

4. Apter, D., and Vihko, R.: Serum pregnenolone, progesterone, 17-hydroxyprogesterone, testosterone and $5 \alpha$-dihydrotestosterone during female puberty. J. Clin. Endocrinol. Metab., 45: 1039 (1977).

5. August, G. P., Hung, W., and Mayes, D. M.: Plasma androgens in premature pubarche: value of $17 \alpha$-hydroxyprogesterone in differentiation from congenital adrenal hyperplasia. J. Pediatr., 87: 246 (1975).

6. Barnes, N. D., Joseph, J. M., Atherden, S. M., and Clayton, B. E.: Functional tests of adrenal axis in children with measurement of plasma cortisol by competitive protein binding. Arch. Dis. Child 47: 66 (1972).

7. Beamer, N., Hagemenas, F. C., and Kittinger, G. W.: Development of cortisol binding in the rhesus monkey. Endocrinology, 93: 363 (1973).

8. Beitins, I. Z., Graham, G. G., Kowarski, A., and Migeon, C. J.: Adrenal function in normal infants and in marasmus and kwashiorkor: Plasma aldosterone concentration and aldosterone secretion rate. J. Pediatr., 84: 444 (1974).

9. Bidlingmaier, F., Wagner-Barnack, M., Butenandt, O., and Knorr, D.: Plasma oestrogens in childhood and puberty under physiologic and pathologic conditions. Pediatr. Res., 7: 901 (1973).

10. Bidlingmaier, F., Versmold, H., and Knorr, D.: Plasma estrogens in newborns and infants. In: Forest, M. G., and Bertrand, J.: Endocrinologie sexuelle de la période périnatale, Vol. 32, pp. 299-314 (Editions INSERM, Paris, 1974)

11. Brown, R. D., Strott, C. A., and Liddle, G. W.: Plasma deoxycorticosterone in normal and abnormal human pregnancy. J. Clin. Endocrinol. Metab., 35: 736 (1972)

12. Cacciari, E., Cicognani, A., Pirazoli, P., Dallacasa, P., Mazzaracchio, M. A., Tassoni, P., Barnardi, F., Salardi, S., and Zappulla, F.: GH, ACTH, LH, and FSH behavior in the first 7 days of life. Acta Paediatr. Scand., 65: 337 (1976).

13. Dillon, M. J., and Ryness, J. M.: Plasma renin activity and aldosterone concentration in children. Br. Med. J., 4: 316, (1975).

14. Dillon, M. J., Gillin, M. E. A., Ryness, J. M., and de Swiet, M.: Plasma renin activity and aldosterone concentration in the human newborn. Arch. Dis. Child., 51: 537 (1976)

15. Edelmann, C. M. Jr., and Spitzer, A.: The maturing kidney. J. Pediatr., 75: 509 (1969).

16. Forest, M. G., Cathiard, A. M., and Bertrand, J.: Evidence of testicular activity in early infancy. J. Clin. Endocrinol. Metab., 37: 148 (1973).

17. Forest, M. G., and Cathiard, A. M.: Ontogenetic study of plasma $17 \alpha$-hydroxyprogesterone in the human. I. Postnatal period: evidence for a transient ovarian activity in infancy. Pediatr. Res., 12: 6 (1978).

18. Gitlow, S. E., Mendlowitz, M., Wilk, K. W., Wilk, S., Wolf, R. L., and Bertani, L. M.: Excretion of catecholamine catabolites in normal children. J. Lab. Clin. Med., 72: 612 (1968)

19. Hadjian, A. J., Chedin, M., Cochet, C., and Chambaz, E. M.: Cortisol binding to proteins in plasma in the human neonate and infant. Pediatr. Res., 9: 40 (1975)

20. Hami, M., Rosler, A., and Rabinowitz, D.: A nonchromatographic radioimmunoassay for $17 \alpha$-hydroxyprogesterone. J. Clin. Endocrinol. Metab., 40: 863 (1975)

21. Hillman, D. A., and Giroud, C. J. P.: Plasma cortisone and cortisol levels at birth and during the neonatal period. J. Clin. Endocrinol. Metab., 25: 243 (1965).

22. Hiner, L. B., Gruskin, A. B., Baluarte, H. J., and Cote, M. L.: Plasma renin activity in normal children. J. Pediatr., 89: 258 (1976).

23. Hughes, I. A., and Winter, J. S. D.: The application of a serum 17-OH-progesterone radioimmunoassay to the diagnosis and management of congenital adrenal hyperplasia. J. Pediatr., 88: 766 (1976).

24. Iturzaeta, N. F. Hillman, D. A., and Colle, E.: Measurement of plasma cortisol in children and adults: A comparison of the double isotope derivative assay, competitive protein-binding analysis and the modified competitive proteinbinding analysis. J. Clin. Endocrinol. Metab., 30: 185 (1970)

25. Jänne, O., Perheentupa, J., Viinikka, L., and Vihko, R.: Plasma pregnenolone, progesterone, 17-hydroxyprogesterone, testosterone, and $5 \alpha$-dihydrotestosterone in different types of congenital adrenal hyperplasia. Clin. Endocrinol., 4: 39 (1975).

26. Janovský, M., Martinek, J., and Stanincova, V.: Antidiuretic activity in the plasma of human infants after a load of sodium chloride. Acta Paediatr. Scand., 54: 543 (1965).

27. Jenner, M. R., Grumbach, M. M., and Kaplan, S. L.: Plasma 17-OH-progesterone in maternal and umbilical cord plasma in children, and in congenital adrenal hyperplasia. Application to neonatal diagnosis. Am. Pediatr. Soc. and Soc Pediatr. Res., Atlantic City, April 29-May 2, 1970, p. 17 (Abstract).

28. Kenny, F. M., Preeyasombat, C., and Migeon, C. J.: Cortisol production rate. II. Normal infants, children, and adults. Pediatrics, 37: 34 (1966).
29. Knorr, D., Bidlingmaier, F., Butenandt, O., Fendel, H., and Ehrt-Wehle, R. Plasma testosterone in male puberty. I. Physiology of plasma testosterone. Acta Endocrinol., 75: 181 (1974)

30. Kowarsky, A., Katz, H., and Migeon, C. J.: Plasma aldosterone concentration in normal subjects from infancy to adulthood. J. Clin. Endocrinol. Metab., 38 489 (1974).

31. Krause, D. K., Schillmöller, U., und Hayduk, K.: Erhöhte Plasma-Renin-Konzentration bei gesunden Säuglingen, Klein- und Schulkindern im Vergleich zu erwachsenen Normalpersonen. Dtsch. Med. Wschr., 97: 1133 (1972).

32. Kruskal, W. H., and Wallis, W. A.: Use of ranks in one criterion variance analysis. J. Am. Statist. Ass., 47: 583 (1952)

33. Lee, P. A., and Migeon, C. J.: Puberty in boys: Correlation of plasma levels of gonadotropins ( $\mathrm{LH}, \mathrm{FSH}$ ), androgens (testosterone, androstenedione, dehydroepiandrosterone, and its sulfate), estrogens (estrone and estradiol) and progestins (progesterone and 17-hydroxyprogesterone). J. Clin. Endocrinol. Metab., 41: 556 (1975).

34. Lee, P. A., Xenakis, T., Winer, J., and Matsenbaugh, S.: Puberty in girls: Correlation of serum levels of gonadotropins, prolactin, androgens, estrogens, and progestins with physical changes. J. Clin. Endocrinol. Metab., 43: 775 (1976).

35. Lippe, B. M., LaFranchi, S. H., Lavin, N., Parlow, A., Coyotupa, J., and Kaplan, S. A.: Serum $17 \alpha$-hydroxyprogesterone, progesterone, estradiol, and testosterone in the diagnosis and management of congenital adrenal hyperplasia. $\mathbf{J}$ Pediatr., 85: 782 (1974).

36. Loras, B., Roux, H., Audi-Parera, L., David, M., and Bertrand, J.: $17 \alpha-$ hydroxyprogesterone plasmatique dans l'hyperplasie congénitale des surrénales par déficit en 21-hydroxylase, traitée et non-traitée. Biomedicine, 21:317 (1974).

37. Mann, H. B., and Whitney, D. R.: On a test of whether one of two random variables is stochastically larger than the other. Ann. Math. Statist., 18: 50 (1947).

38. Minick, M. C., and Conn, J. W.: Aldosterone excretion from infancy to adult life. Metabolism, 13: 681 (1964)

39. Parth, K., Brunel, R., Zimprich, H., and Holzer, H.: Plasmaaldosteron im Kindesalter. Helv. Paediatr. Acta, 30: 487 (1976)

40. Pham-Huu-Trung, M. T., Gourmelen, M., and Girard, F.: The simultaneous assay of cortisol and $17 \alpha$-hydroxyprogesterone in the plasma of patients with congenital adrenal hyperplasia. Acta Endocrinol., 74: 316 (1973).

41. Pipkin, F. B., and Smales, O. R. C.: A study of factors affecting blood pressure and angiotensin II in newborn infants. J. Pediatr., 91: 113 (1977).

42. Raux-Eurin, M. C., Pham-Huu-Trung, M. T., Marrec, D., and Girard, F.: Plasma aldosterone concentrations during the neonatal period. Pediatr. Res., 11: 182 (1977).

43. Sassard, J., Sann, L., Vincent, M., Francois, R., and Cier, J. F.: Plasma renin activity in normal subjects from infancy to puberty. J. Clin. Endocrinol. Metab., 40: 524 (1975)

44. Seely, J. R.: Adrenal function in newborns: Methodology and perinatal circulating steroid patterns. Am. J. Dis. Child., 102: 474 (1961).

45. Siegler, R. L., Crouch, R. H., Hackett, T. N., Walker, M., and Jubiz, W. Potassium-renin-aldosterone relationships during the first year of life. J. Pediatr., 91: 52 (1977).

46. Sippell, W. G., Bidlingmaier, F., Becker, H., Brünig, T., Dörr, H., Hahn, H. Golder, W., Hollmann, G., and Knorr, D.: Simultaneous radioimmunoassay of plasma aldosterone, corticosterone, 11-deoxycorticosterone, progesterone. 17-hydroxyprogesterone, 11-deoxycortisol, cortisol, and cortisone. J. Steroid Biochem., 9: 63 (1978).

47. Sippell, W. G., Bidlingmaier, F., and Knorr, D.: Radioimmunoassay and related procedures in medicine 1977. Proceedings of a Symposium, Vol. I, p. 229 (International Atomic Energy Agency, Vienna, 1978).

48. Sippell, W. G., Becker, H., Versmold, H. T., Bidlingmaier, F., and Knorr, D. Longitudinal studies of plasma aldosterone, corticosterone, deoxycorticosterone, progesterone, 17-hydroxyprogesterone, cortisol, and cortisone determined simultaneously in mother and child at birth and during the early neonatal period. I. Spontaneous delivery. J. Clin. Endocrinol. Metab., 46: 971 (1978)

49. Sippell, W. G., Gaede, P., Fleischmann, O., Bidlingmaier, F., Knorr, D., and Troelle, D.: Plasma concentrations of eight unconjugated steroids in mother and fetoplacental unit at term delivery. Acta Endocrinol., 87 (Suppl. 215): 34 (1978).

50. Šolc, J., and Knorr, D.: Untersuchungen über die Tetrahydroaldosteron Ausscheidung im Kindesalter durch Gaschromatographie mit Elektroneneinfangdetektor (ECD). Acta Endocrinol., 70: 533 (1972).

51. Stalker, H. P., Holland, N. H., Kotchen, J. M., and Kotchen, T. A.: Plasma renin activity in healthy children. J. Pediatr., 89: 256 (1976).

52. Stark, P., Beckerhoff, R., Leumann, E. P., Vetter, W., and Siegenthaler, W. Control of plasma aldosterone in infancy and childhood. Helv. Paediatr. Acta, 30: 349 (1975).

53. Tanner, J. M.: The development of the reproductive system. Growth at Adolescence, 2nd Edition p. 28 (Blackwell Scientific Publications, Oxford, 1962).

54. Tea, N. T., Castanier, M., Roger, M., and Scholler, R.: Simultaneous radioimmunoassay of plasma progesterone and 17-hydroxyprogesterone. Normal values in children, in men and in women throughout the menstrual cycle and in early pregnancy. J. Steroid Biochem., 6: 1509 (1975).

55. Weidmann, P., deMyttenaere-Bursztein, S., Maxwell, M. H., and deLima, J. Effect of aging on plasma renin and aldosterone in normal man. Kidney Intern., 8: 325 (1975).

56. Weldon, V. V., Kowarski, A., and Migeon, C. J.: Aldosterone secretion rates in normal subjects from infancy to adulthood. Pediatrics, 39: 713 (1967)

57. Winter, J. S. D., and Faiman, C.: Pituitary-gonadal relations in female children 
and adolescents. Pediatr. Res., 7: 948 (1973).

58. Winter, J. S. D., Hughes, I. A., Reyes, F. I., and Faiman, C.: Pituitary-gonadal relations in infancy: 2 . Patterns of serum gonadal steroid concentrations in man from birth to 2 years of age. J. Clin. Endocrinol. Metab., 42: 679 (1976).

59. The trivial names and abbreviations used are: $\mathrm{A}$ : aldosterone, 11 $\beta, 21$-dihydroxy3,20-dioxo-4-pregnene - 18-al; B: corticosterone, 11 $\beta, 21$-dihydroxy-4-pregnene3,20-dione; DOC: 11-deoxycorticosterone, 21-hydroxy-4-pregnene-3,20-dione: P: progesterone, 4-pregnene-3,20-dione; 17-OHP; 17-hydroxyprogesterone, 17 hydroxy-4-pregnene-3,20-dione; F: cortisol, $11 \beta, 17 \alpha, 21$-trihydroxy-4-pregnene-3,20-dione; E: cortisone, 17 $\alpha, 21$-dihydroxy-4-pregnene-3,11,20-trione.

60. The authors thank Ms. Gisela Putz and Ms. Marianne Scheuerecker for their expert technical assistance, Ms. Eva Zierbeck, R. N., of the Pediatric Outpatient
Department for her help in collecting blood samples, and Mrs. Julika Willumeit for typing the manuscript.

61. Data from this study were presented in part at the Fifth International Congress on Hormonal Steroids, New Delhi, India, October 29-November 4, 1978.

62. This research was supported in part, by the Deutsche Forschungsgemeinschaft (SFB 51, C-10), and by grant no. 01 VL 077 from the German Federal Ministry for Research and Technology (BMFT).

63. Requests for reprints should be addressed to: P.D. Dr. Wolfgang G. Sippell, Kinderklinik der Universität München, Lindwurmstr. 4, D-8000 München 2, West Germany.

64. Received for publication October 17, 1978

65. Accepted for publication January 23, 1979.

Copyright (C) 1980 International Pediatric Research Foundation, Inc.

Printed in U.S.A 